eminent a thinker. My object in so often taking the line of a fault-finder is mainly this. As yet there is but a limited number of students who seriously occupy themselves with the problem of the development of religious ideas as viewed from the ethnological standing-point. Prrbably in a few years' time public interest in this great problem will be much wider and deeper, a result to which the present work must largely contribute. When this happens, a vast controversy will no doubt set in, for which it will be advantageous to ethnologists to be well prepared beforehand. The previous interval may therefore be well turned to account in settling discrepancies as to subordinate points, so that the weaker parts of the theory of animistic development may be cut out and their places supplied with stmuger evidence and reasoning. Mr. Spencer's work seems to me to do this in several branches of the subject, and notably as to ancestor-worship and fetishism. It is the best acknowledgment of the importance of the work at once to raise oljection to the points which seem objectionable, that it may be settled as soun as possible whether the author will be able to maintain them or not.

EDWard B. TyLor.

\title{
1I.-CONSCIOUSNESS AND UNCONSCIOUSNESS.
}

SCreNce demands precision of terms; and in this sense Condillac was justified in defining it "unc langue bien faite". The sciences of Measurement are exact because of the precision of their terms, and are powerful because of their exactness. The sciences of Classification cannot aspire to this precision, and therefore, although capable of attaining to a fuller knowledge of phenoniena than can be reached by their rivals, this advantage of a wider range is accompanied by the disadvantage of a less perfect exposition of results. While physicists and chemists have only to settle the significance of the facts observed, biologists and social theorists have over and above this to settle the significance of the terıns they employ in expressing the facto observed. Hence more than half their disputes are at bottom verbal.

This is markedly the crse in the question of Automatism. One man declares that animals are automata; another that they are conscions automata ; and while it is quite possible to hold these views and not practically be in disagreement with the views

\footnotetext{
- From a forthconing volume on The Physical Basis of Mind.
} 
of ordinary men, or indeed with the views of spiritualist and materialist philosophers, we can never be sure that the advocates of Automatism do not mean what they are generally understood to mean. If a man says that by an automaton he does not here mean a machine, such as a steam-engine or a watch, but a vital mechanism which has its parts so adjusted that its actions resemble those of a machine; and if he adds that this automaton is also conscious of some of its actions, though unconscious of others, we can only object to his using terms which have misleading connotations. If he mean by "conscious automata," that animals are mechanisms moved on "purely mechanical principles," their consciousness having nothing whatever to do with the production of their actions, then indeed our objection is not only to his use of terms, but to his interpretation of the facts.

The questions of fact are two: Are animal mechanisms rightfully classed beside machines ? and, Is consciousness a coefficient in the actions of aninal mechanism ? The first has already been answered; the second demands a preliminary settlement of the terms "conscious," "unconscious," "voluntary," and "involuntary". The aim of Physiology is to ascertain the particulnr combinations of the elementary parts involved in each particular function-in a word, the mechanism of organic phenomena; and the modern Reflex Theory is an attempt to explain this mechanism on purely mechanical principles, without the co-operation of other principles, especially those of Sensation and Volition. It is greatly aided by the ambiguity of current terms. We are accustomed to speak of certain actions as being performed unconsciously or involuntarily. We are also accustomed to say that Consciousness is necessary to transform an impression into a sensation, and that Volition is the equivalent of conscious effort. When, therefore, unconscious and involuntary actions are recorded, they seem to be actions of an insentient mechanism. The Reflex Theory once admitted, a rigorous logic could not fail to extend it to all animal actions.

I reject the Reflex Theory, on grounds hereafter to be urged, but at present call attention to the great ambiguity in the terms "conscious" and "unconscious". In one sense no definition of Consciousness can be satisfactory, since it designates an ultimate fact which cannot therefore be made more intelligible thian it is already. In another sense no definition is needed, since every one knows what is meant by saying, "I am conscious of such a change, or such a movement". It is here the equivalent of Feeling. To be conscious of a change, is to feel a change. If we desire to express it in physiological terms, we must define Consciousness-"a function of the organism"; and this definition we shall find eminently useful, because the organism being a vital 
mechanismand the integrity of that mechanism being necessary for the integrity of the function, while every variation of the mechanism will bring a corresponding variation of the function, we shall have an objective guide and standard in our inquiries. Organisms greatly differ in complexity, yet because they also agree in the cardinal conditions of Vitality, among which Sensibility is one, we conclude that they all have Feeling; but the Feeling of the one will differ from that of another, according to the complexity of the sentient mechanism in each. The perfection of this mechanism lies in the co-ordination of its parts, and the consensus of its sentient activities; any disturbance of that consensus must cause a modification in the total consciousness; and when the disturbance is profound the modification is marked by such terms as "insanity," "loss of consciousness," "insensibility". These terms do not imply that the sentient organs have lost their Sensibility, but only that the disturbed mechanism has no longer its normal consensus, no longer its normal state of Consciousness. Each ongan is active in its own way so long as its own mechanism is preserved ; but the united action of the organs having been disturbed, their resultant function has been altered. Hence in a fit of Epilepsy there is a complete absence of some normal reactions, with exaggeration of others. In a state of Coma there is no spontaneity - none of the manifold adaptations of the organism to fluctuating excitations, external and interval, observable in the normal state. The organism still manifests Sensibility-but this is 80 unlike the manifestations when its mechanism is undisturbed (and necessarily go since the Sensibility varies with the mechanism) that it is no longer called by the same name. In the normal organism Sensibility means Feeling, or Consciousness; but in the abnormal organism there is said to be a "loss of Consciousness". What the physiologist or the physican means by the phrase "loss of Cunsciousness" is intelligible, and for his purpose unobjectionable. He observes many organic processes going on undisturbed-the unconscious patient breathes, secretes, moves his limbs, \&c. These processes are referred to the parts of the mechanism which are not disturbed ; they are obviously independent of the adjustment of the mechanism which, by its consensus, has the special resultant named Consciousness; he therefore concludes that these, and many other organic processes, which are neither accompanied nor followed by discriminated feelings, are the direct consequences of the stimulated mechanism. He never hesitates to adopt the popular language, and say, "We sometimes act unconsciously, perceive unconsciously, and even think unconsciously, all by the simple reflex of the mechanism ".

Now ubserve the opening for crror in this language. The actions 
are said to go on unconsciously, and, because unconsciously, as pure reflexes, which are then assigned to an insentient mechanism, and likened to the actions of machines. But, as I hope hereafter to make evident, the reflex mechanism necessarily involves Sensibility; and therefore reflex actions may be unaccompanied by Cousciousness-in one mesning of that term-without ceasing to be sentient: the feelings are operative, although not discriminated. On the other hand, there is another and very general meaning of the term Consciousness, which is the equivalent of Sentience.

In discussing Automatism, or the Reflex Theory, it is absolutely necessary that we should first settle the meaning we assign to the term Consciousness. The laxity with which the term is used may be seen in the enumeration occupying six pages of Professor Bain's account of the various meanings. Psychology is often said to be "the science of the facts of Consciousness"; and the Brain is often assigned "as the organ of Consciousness". Yet there are many mental processes, and many cerebral processes, which are declared to be unconscious. Obviously if Consciousness is the function of the Brain, there can be no cerebral activity which is unconscious; just as there can be no activity of the lungs which is not respiratory. Usage therefore points to a general and a special sense of the term. The general usage identifies it with Sensibility, in its subjective aspect as Sentience, including all psychical states, both those classed under Sensation, und those under Thought. These states are the "facts of consciousness" with which Psychology is occupied. In the special usage it is distinguished from all other psychical states by a peculiar reflected feeling of Attention, whereby we not only have a sensation, but also feel that we have it; we not only think, but are conscious that we are thinking; not only act, but are conscious of what we do. It is this which Kant indicates when he defines it "the subjective form accompanying all our conceptions (Begriffe)"; and Jessen when he defines it "the internal knowing of our knowing, and in itself reflected knowing "."

We shall often have to recur to this general and this special meaning, both of which are too firmly rooted for any successful attempt to displace them. The fact that some organic processes and some mental processes take place now consciously and now unconsciously, i.e., now with the feeling of reflected attention,

- "Das Bewrusstwerden ist nichts Anderes als ein weiter fortgeschrittenes Erinnern oder Neuwerden des von aussen anfgenommenen Wissens, ein innerliches Wissen dieses Wissens oder ein in sich reflectirtes Wisson."-Jessex: Versuch einer Wisenechaftlichen Begrindung der Prycholngie, 1855, p. 477. 
and now with no such feeling, assuredly demands a corresponding expression; nor, in spite of inevitable ambiguities, is there ground for regretting that the expression chosen should be only an extension of the expression already adopted for all other states of Sentience. A sentient or conscious state can only be a state of the sentient organism, itself the unity of many organs, each having its Sensibility. There is more or less consensus, but there is no introduction of a new agent within the organisin, connecting what was physical impression into mental reaction. From first to last there has been nothing but neural processes, and combinations of such processes-which, viewed subjectively, are sentient processes. Thus the gradations of sensitive reaction are Sentience, Cousentience, and Consciousness, which are represented in the Logic of Feeling and the Logic of Signs. The familiar term Conseience will then represent the Logic of Conduct. Thus understood, we may say that a man sometimes acts unconsciously, or thinks unconsciously, although his action and thought are ruled by Consentience, as he sometimes acts and thinks unconscientiously, although he is not without obedience to Conscience on other occasions. The feeling which determines an action is operative, although it may not be discriminated from simultaneous feelings. When this is the case, we say the feeling is unconscious; but this no more means that it is a purely physical process, that it takes place outside the sphere of Sentience, than the immoral conduct of a man would be said to be mechanical, and not the conduct of a moral agent. There is undoubtedly a marked distinction expressed in the terms Consciousness and Unconsciousness, but it is not that of Mental and Physical, it is that of extremes such as Light and Darkness. Just as Darkness is a positive optical sensation very different from mere privation-just as it replaces the sensation of Light, blends with it, struggles with it, and in all respects differs from the absence of all optical sensibility in the skin ; so Unconsciousness struggles with, blends with, and replaces Consciousness in the organism, and is a positive state of the sentient organism, not to be confounded with a mere negation of Sentience; above all, not to be relegated to merely mechanical processes.

Kemember that, strictly speaking, Consciousness is a psycholngical not a physiological term, and is only used in Physiolony on the assumption that it is the subjective equivalent of an objective process. To avoid the equivoque of " unconscious sensation," we may substitute the terin "unconscious neural process"; and as all neural processes imply Sensibility, which in the subjective aspect is Sentience, we say that Sentience has various jnodes and degrees-such as Perception, Ideation, Emotion, Volition, which may be conscious, sub-conscious, or unconscious. 
When Leibnitz referred to the fact of "obscure ideas," and modern writers expressed this fact as "unconscious cerebration," the one phrase did not imply a process that was other than mental, the other phrase did not imply a process that was other than physiological; both indicated a mode of the process known as Consciousness under other modes. There are different neural elements grouped in Ideation and Emotion; there are different neural elements grouped in Consciousness, Sub-consciousness, and Unconsciousness; but one tissue with one property is active in all.

The nervous organism is affected as a whole by every affection of its constituent parts. Every excitation, instead of terminating with itself-as is the case in most physical processes-or with the motor impulse it excites, is propagated throughout the continuous tissue, and thus sends a thrill throughout the organism. The wave of excitation in passing onwards beats against variously-grouped elemento - temporary and permanent centres-disturbing their balance more or less, and liberating the energy of some, increasing the tension of others, but necessarily affecting all Those groups which have their energy liberated set up processes that are either discriminated as sensations, or are blended with the general stream, according to their relative energy in the consensus. Thus the impulse on reaching the centres for the heart, lungs, legs, and tail excites the innervation of these organs; but as these are only parts of the organism, and as all the parts enter the consensus, and Consciousness is the varying resultant of this ever-varying consensus, the thrill which any particular stimulus excites will be unconscious, sub-conscious, or conscious, in proportion to the extent of the irradiated disturbance, which will depend on the statical conditions of the centres at the moment. A sound sends a thrill which excites emotion, causes the heart to beat faster, the muscles to quiver, the skin-glands to pour forth their secretion; yet this same sound heard by another man, or the same man under other conditions, physical or historical, merely sends a faint thrill, just vivid enough to detach itself as a sensation from the other simultaneous excitations; and the same sound may excite a thrill which is so faint and fugitive rs to pass unconsciously. Physiological and psychological inductions assure us that these are only differences of degree. The same physiological effects accompany the conscious and unconscious state. Every sensory impression, no matter whether discriminated or not, affects the circulation and develops heat. The blood-vessels of the part impressed expand, vessels elsewhere contract-a change in the blood pressure has been effected, which of course implies that the whole organism has been 
affected. Delicate instruments prove that at the time a sensation is produced the temperature of the brain is raised. The same is true of ideation. Mosso has invented a method of registering the effect of thought on the circulation. He finds ideation accompanied by a contraction of the peripheral vessels proportionate to the degree of intellectual effort. A young man translating Greek showed greater contraction than when he was translating Latin. During sound sleep-when we are said to be unconscious-sudden noises always cause contraction of the peripheral vessels. Psychological observation assures us that the conscious and unconscious states were both consentient, and were both operative in the same degree. The absorbed thinker threads his way through crowded streets, and is subconscious and unconscious of the various sights, sounds, touches, and muscular movements which make up so large a portion of his sentient excitation at the time; yet he deftly avoids obstacles, hears the sound of a hurried step behind him, recognises an interesting object directly it presents itself, and can even recall in Memory many of the uninteresting objects which he passed in sub-conscious and unconscious indifference.

On all grounds, therefore, we must say that between conscious, sub-conscious, and unconscious states the difference is only of degree of complication in the neural processes, which by relative preponderance in the consensus determine a relative diserimination. We can only discriminate one thrill at a time; but the neural excitations simultaneously pressing towards a discharge are many; and the conditions which determine now this, and now the other excitation to predominate by its differential pressure, are far beyond any mechanical estimate. I mention this because the advocates of the Reflex Theory maintain that the neural processes are the same whether a sensation be produced or not; and that since the same actions follow the external stimulation whether sensation be produced or not, this proves the actions to be purely inechanical. I reply, the neurnl processes are not the same throughout in the two cases-otherwise the effects would be the same. You might as well say, "Since the explosion of the gun is the same, whether shotted or not, a blank cartridge will kill"; but if you tell me that your gun killed the bird, I declare that the cartridge was not a blank one. Whether the explosion of the gun also produced terror in one bystander, curiosity in a second, and attracted no notice from a third, will be altogether another matter. In like manner the sensory impression which determines a movement may or may not be accompanied or followed by other sentient states; the fact of such movement is evidence of its sentient antecedent; and an external stimulus that will produce this neural process, 
and this consequent movement, must produce a feeling, although not necessarily a discriminated sensation. Now since, for discrimination, other neural processes must co-operate, we cannot say that in the two cases the neural processes have been the same throughout; nor because of this difference can we say that the process of the undiscriminated sensation is a mechanical, not a sentient process.

The need of recognising Consciousness and Consentience as degrees of energy and complexity in sentient states is apparent when we consider animal phenomena. Has a bee consciousness? Has a snail volition? or are they both insentient mechanisms ? All inductions warrant the assertion that a bee has thrills propagated throughout its organism by the agency of its nerves; and that some of these thrills are of the kind called sensations - even discriminated sensations. Nevertheless we may reasonably doubt whether the bee has sentient states resembling otherwise than remotely the sensations, emotions, and thoughts which constitute human Consciousness, either in the general or the special sense of that term. The bee feels and reacts on feelings; but its feelings cannot closely resemble our own, because the conditions in the two cases are different. The bee may even be said to think (in so far as Thought means logical combination of feelings), for it appears to form Judgments in the sphere of the

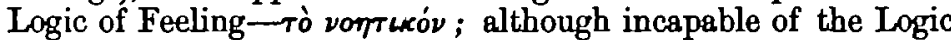
of Signs-tò diavontıkóv. We should therefore say the bee has Consentience, but not Consciousness-unless we accept Consciousness in its general signification as the equivalent of Senticnce. The organism of the bee differs from that of a man, as a mud hut from a marble palace. But since underlying these differences there are fundamental resemblances, the functious of the two will be fundamentally alike. Both have the function of Sentience; as mud hut and palace have both the office of sheltering.

The question of Volition needs a separate discussion. Restricting ourselves here to that of Consciousness, and recalling the distinction of the two meanings of the term, we now approach the question of Unconsciousness. Are we to understand this term as designating a purely physical state in contrast to the purely mental state of Consciousness; or only as designating a difference of degree? This is like asking whether Light and Darkness are both optical feelings, or one an optical feeling and the other a physical process? On the Reflex Theory, no sooner does a vital and mental process pass from the daylight of Consciousness, or twilight of Sub-consciousness, into the darkness of Unconsciousness, than the whole order of phenomena is abruptly changed, they cease to be vital, mental, 
and lapse into physieal, mechanical processes. The grounds of this conclusion are, first, the unpsychological assumption that the unconscious state is out of the sphere of Sentience; and secondly, the unphysiological assumption that the Brain is the only portion of the nervous system which has the property of Sensibility. Restate the conclusion in different terms and its fallacy emerges: "organic processes suddenly cease to be organic, and become purely physical by a slight change in their relative position in the consensus; the organic process which was a conscious sensation a moment ago, when its energy was not balanced by some other process, suddenly falls from its place in the group of organic phenomena-sentient phenomena - to sink into the group of inorganic phenomena now that its energy is balanced ". Consider the parallel case of Motion and Rest in the objective sphere. They are two functions of the co-operant forces, one dynamic, the other static; although markedly distinguishable as functions, we know that they are simply the cooperant forces now unbalanced and now balanced; what we call Rest is also a product of moving forces, each of which is operant, and will issue in a definite resultant when its counter-force is removed. Motion and Rest are correlatives, and both belong to the sphere of Kinetics. In like manner Consciousness and Unconsciousness are correlatives, both belonging to the sphere of Sentience. Every one of the unconscious processes is operant, changes the general state of the organism, and is capable of at once issuing in a discriminated sensation when the force which balances it is disturbed. I was unconscious of the scratch of my pen in writing the last sentence, but I am distunctly conscious of every scratch in writing this one. Then, as now, the scratching sound sent a faint thrill through my organism, but its relative intensity was too faint for discrimination; now that I have redistributed the co-operant forces, by what is called an act of Attention, I hear distinctly every sound the pen produces.

The inclusion of Sub-conscionsness within the sentient sphere is obvious; the inclusion of Unconsciousness within that sphere may be made so, when we consider its modes of production, and compare it with the extra-sensible conception of molecules and atoms. The Matter which is sensible as masses, may be divided into molecules, which lie beyond the discrimination of sense; and these again into atoms, which are purely ideal conceptions; but because molecules are proved, and atoms are supposed, to

- In conmon langarge a stone or a tree is said to be unconscious; but this is an anthropomorphic extension of the term. In strictness we should no more speak of unconscionsmess outside the ephere of Sentience than of darkness outside the ophere of Vision. 
have material properties, and to conform to sensible canons of the objective world, we never hesitate to class them under the head of Matter; nor do we imagine that in passing beyond the discrimination of Sense they pass into the subjective region. They are still physical, not mental facts. So with Sentience. We may trace it through infinite gradations from Consciousness to Sub-consciousness, till it fades away in Unconsciousness; but from first to last the processes have been those of a sentient organism; and by this are broadly distingushed from all processes in anorganisms. The movement of a limb has quite different modes of production from the movement of a wheel; and among its modes must be included those of Sensibility, a peculiarly vital property. Oxidation may be slow or rapid, manifesting itself as combustion, heat, or flame, but it is always oxidation-always a special chemical phenomenon. And so the neural process of Sentience, whether conscious, sub-conscious, or unconscious, is always a state of the sentient organism. If a material process does not change its character, and become spiritual, on passing beyond the range of sensible appreciation, why should a psychical process become material on passing beyond the range of discrimination? If we admit molecules as physical units, sentient tremors are psychical units. The extra-sensible molecules have indeed their subjective aspect, and only enter perception through the "greeting of the spirit". The sentient tremors have also their objective aspect, and cannot come into existence without the neural tremors, which are their physical conditions.

It is only by holding fast to such a conception that we can escape the many difficulties and contradictions presented by unconscions phenomena, and explain many physiological and psychological processes. Descartes-followed by many philosophers-identified Consciousness with Thought. To this day we constantly hear that to have a sensation, and to be conscious of it, is one and the same state; which is only admissible on the understanding that Consciousness means Sentience, and Sentience the activity of the nervous system viewed subjectively. Leibnitz pointed out that we have many psychical states which are unconscious states-to have an ides and be conscious of it, are, he said, not one but two states. The Consciousness by Descartes created into an essential condition of Thought, was by Leibnitz reduced to an accompaniment which not only may be absent, but in the vast majority of cases is absent. The teaching of most modern psychologists is that Consciousness forms but a small item in the total of psychical processes. Unconscious sensations, ideas, and judgments are made to play a great part in their explanations. It is very certain that in 
every conscious volition-every act that is so characierisedthe larger part of it is quite unconscious. It is equally certain that in every perception there are unconscious processes of reproduction and inference-there is much that is inplicit, some of which cannot be made explicit_a "middle distance" of sub-consciousness, and a "background" of unconsciousness. But, throughout, the processes are those of Sentience.

Unconsciousness is by some writers called latent Conscionsness. Experiences which are no longer manifested are said to be stored up in Memory, remaining in the Soul's picture-gallery, visible directly the shutters are opened. We are not conscious of these feelings, yet they exist as latent feelings, and become salient through association. As a metaphorical expression of the familiar facts of Memory this may pass, but it has been converted from a metaphor into an hypothesis, and we are supposed to have feelings and ideas, when in fact we have nothing more than a modified dispositzon of the ormanismtemporary or permanent-which when stimulated will respond in this modified manner. The modification of the organism when permanent becomes hereditary; and its response is then called an instinctive or automatic action. And as actions pass by degrees from conscious and voluntary into sub-conscious and sub-voluntary, and finally into unconscious and involuntary, we call them volitional, secondarily automatic, and automatic. If any one likes to say the last are due to latent consciousness, I shall not object. 1 only point to the fact that the differences here specified are simply differences of degree-all the actions are those of the sentient organism.

Picture to yourself this sentient organism incessantly stimulated from without and from within, and adjusting itself in response to such stimulations. In the blending of stimulations, modifying and arresting each other, there is a fluctuating " composition of forces,". with ever-varying resultants. Besides the stream of direct stimulations, there is a wider stream of indirect or reproduced stimulations. Together with the present seusation there is always a nore or less complex group of revived sensations, the one group of neural tremors being organically stimulated by the other. An isolated excitation is impossible in a continuous nervous tissue; an isolated feeling is impossible in the consensus or unity of the sentient organisn. The term Soul is the personification of this complex of present and revived feelings, and is the substratum of Consciousness (in its general sense), all the particular feelings being its states. To repeat an illustration used in my first volume, we may compare Consciousness to a mass of stationary waves. If the surface of a lake be set in motion each wave diffuses itself over 


$$
\text { The 'Suppression' of Egoism. }
$$

the whole surface, and finally reaches the shores, whence it is reflected back towards the centre of the lake. This reflected wave is met by the fresh incoming waves, there is a blending of the waves, and their product is a pattern on the surface. This pattern of stationary waves is a fluctuating pattern, because of the incessant arrival of fresh waves, incoming and reflected. Whenever a fresh stream enters the lake (i.e., a new sensation is excited from without), its waves will at first pass over the pattern, neither disturbing it nor being disturbed by it; but after reaching the shore the waves will be reflected back towards the centre, and there will more or less modify the pattern.

George Hexry Lewes.

\section{III.-THE ' SUPPRESSION' OF EGOISM.}

As Mr. Sidgwick's book on The Metholds of Ethics seems thought to have cast some discredit on the system which he calls 'Egoistic Hedonism,' and which indeed he himself distinctly claims to have 'suppressed,' I propose in this paper to consider his treatment and non-treatment of that system.

Of the principle that the Ethical end of Action is Pleasure of the Actor, there are three distinct and independent proofs, which I may call respectively the Physical, the Introspective, and the Intuitional. $\mathrm{My}$ aim will be to show that of these Mr. Sidgwick has omitted the first, has not disproved the second, and has established the third. If any one of these propositions be accurate, then, since one proof is sufficient to prove, and truth is not made doubtful by the possibility of reaching it falsely, Egoism will be untouched by Mr. Sidgwick's attack. Instead of the 'suppressor' of Egoism, I hope to show him its unwilling prophet. Let me remark at the outset that it is the Science, not the Art, of Morality that I am concerned with; the truth of principles, not the method of using them. If a man can establish a thing to be true, he need not care for its practical application : that will take care of itself.

- Notwithstanding that so mnch space has already been given in MixD to the criticism of Mr. Sidgwick's work, I do not hesitate to print the following article, written as it is from a fresh point of view. The iuterest thut coutinues to be excited by The Hethads of Ethics, shown also in the recent appearsace of Mr. F. H. Bradley's pamphlet (Mr. Sidgrick's Hedoniom, King \& Co.), is a notable fuct in English philosophy at the present dyy, and there should remsin due record of it in the pages of this Journal. EDITOR. 